\title{
Leaders
}

\section{Reducing cumulative lifetime disability: the compression of morbidity}

The compression of morbidity hypothesis envisages a potential reduction of overall morbidity and of health care costs, now heavily concentrated in the senior years, by compression of the period of morbidity between an increasing average age of onset of disability and the age of death, increasing perhaps more slowly. ${ }^{1}$ The healthy life is seen as a one that is vigorous and vital until shortly before its natural close. Intuitively, the concept of delaying the onset of disability through prevention of disease and maintenance of good function seems natural enough. However, in the early and middle years of this century most observers believed that there was movement away from this ideal, with a steady increase in the proportion of a typical life spent ill or infirm. ${ }^{23}$ The previously prevalent acute illnesses had given way to chronic diseases with longer periods of morbidity. As people took better care of themselves and lived longer, the contrarians suggested that they would live into those later years in which disability is greatest and would experience an increase in overall lifetime disability. Such critics feared that good behavioral health habits would lead to an epidemic of Alzheimer's disease and a huge population of enfeebled demented elders who would pose an immense strain upon medical care resources. ${ }^{4}$

Fortunately for the healthy life, these fears are unfounded. Firstly, life expectancy from advanced ages has plateaued rather than having increased markedly as predicted. In the United States, the life expectancy of women from age 65 has increased only 0.3 years over a 15 year period. From age 85, female life expectancy in the United States has been constant at 6.0 years since $1980 .{ }^{5}$ Secondly, recent longitudinal data document the ability to greatly postpone the onset of disability with age. For the past 13 years our research group at Stanford has studied the effects of long distance running on patient outcomes in 537 members of a runners club, with participants at least 50 years old, compared with 423 age matched community controls. ${ }^{6}$ The study was designed as a test of the compression of morbidity hypothesis. Appropriate controls of self selection bias were included and disability levels were assessed yearly, allowing the area under the disability curve to be assessed. Runners who exercised vigorously for an average of 280 minutes a week delayed the onset of disability by about 10 years compared with controls. Both male and female runners increased disability at a rate only one third of that of the controls, after adjustment for age, initial disability, educational level, smoking behaviour, body mass index, history of arthritis, and the presence of co-morbid disease. As these subjects moved from age 58 toward age 70 , the differences in physical function between the exercising and the control population increased, rather than decreased. Lifetime disability in exercisers is only one third to one half of that in sedentary individuals. ${ }^{67}$

In the University of Pennsylvania study, we looked at 1741 university attendees, surveyed in 1962 at an average age of 43 , and then annually since 1986 . This unique data set contains over 50 years of longitudinal follow up since the participants' days at university. Health risk strata were developed for persons at high, moderate, and low risk, based on the three risk factors of smoking, body mass index, and lack of exercise. ${ }^{8}$ Cumulative disability from 1986 (at an average age of 67) to 1994 (at an average age of 75) or until death served as a surrogate for lifetime disability. Persons with high health risks in 1962 or in 1986 have about twice the cumulative disability of those with low health risks. Results were consistent across survivors, deceased, men, women, and over the last one and two years of observation. Deceased low risk subjects had had only one half of the disability of high risk subjects in their last one and two years of life. High risk subjects, despite having increased mortality, had greatly increased lifetime disability. Onset of disability was postponed by about 7.75 years in the low risk stratum as compared with the high risk stratum. The $100 \%$ reduction in disability rates was balanced against only a $50 \%$ reduction in mortality rates, yielding compression of morbidity.

The compression of morbidity is readily demonstrable in those who exercise vigorously compared with those who do not, and those with low behavioral health risks versus those with high, and those with high educational attainment as compared with low. ${ }^{9} 10$ Health risk behaviours as determined in mid life and late adulthood strongly predict subsequent lifetime disability. Both cumulative morbidity and morbidity at the end of life are decreased in those with good health habits. ${ }^{11}$ Morbidity is postponed and compressed into fewer years in those with fewer health risks. The paradigm of a long healthy life with a relatively rapid terminal decline represents an attainable ideal. Health policies must be directed at modifying those health risks that precede and cause morbidity if this ideal is to be approached for a population. ${ }^{12} 13$

JAMES F FRIES

Professor of Medicine, Stanford University School of Medicine, Palo Alto, CA 94304, USA

1 Fries JF. Aging, natural death, and the compression of morbidity. $N$ Engl $\mathcal{F}$ Med 1980;303:130-6.

2 Gruenberg EM. The failure of success. Milbank $Q$ 1977;55:3-34

3 Verbrugge LM. Longer life but worsening health? Trends in health and mortality of middle-aged and older persons. Milbank $Q$ 1984;62:475-519.

Myers GC, Manton KG. Compression of mortality: myth or reality? Gerontologist $1984 ; 24: 346-53$.

5 Kranczer S. US life expectancy. Statistical Bulletin 1997 Oct-Dec:2-8.

5 Kranczer S. US life expectancy. Statistical Bulletin 1997 Oct-Dec:2-8.
6 Fries JF, Singh G, Morfeld D, et al. Running and the development of disability with age. Ann Intern Med 1994;121:502-9.

7 Stewart AL, King AC, Haskell WL. Endurance exercise and health-related quality of life in 50-65 year-old adults. Gerontologist 1993;33:782-9.

8 Vita AJ, Terry RB, Hubert HB, et al. Aging, health risks, and cumulative disability. $N$ Engl f Med 1998;338:1035-41.

House JS, Kessler RC, Herzog AR, et al. Age, socioeconomic status, and health. Milbank Mem Fund $Q$ 1990;68:383-411.

10 Leigh JP, Fries JF. Education, gender and the compression of morbidity. Int f Aging Hum Dev 1994;39:233-46.

11 Campion EW. Aging better. N Engl f Med 1998;338:1064-6.

12 Nusselder WJ, Mackenbach JP. Rectangularization of the survival curve in the Netherlands, 1950-1992. Gerontologist 1996;36:773-82.

13 Fries JF, Koop CE, Beadle CE, et al. Reducing health care costs by reducing the need and demand for medical services. N Engl f Med 1993;329:321-5. 